\title{
Erosão fluvial sobre rochas vulcânicas: algumas inferências a partir de segmentos côncavos de perfis longitudinais
}

\author{
Adalto Gonçalves Lima ${ }^{1 *}$
}

\begin{abstract}
Resumo A pesquisa procurou identificar os fatores que controlam a homogeneidade da resistência à erosão fluvial sobre rochas vulcânicas e que levam à formação, por conseguinte, de segmentos côncavos nos perfis longitudinais dos rios. Por meio de levantamento cartográfico e em campo de dados geológicos e geomorfológicos e utilizando a relação decliveárea, investigou-se o papel das características litológicas e do fraturamento tectônico sobre a formação dos segmentos côncavos, em um pequeno canal instalado sobre riodacitos e basaltos da Formação Serra Geral, no Paraná. A relação declive-área, na forma de uma função potência, permitiu identificar a existência de segmentos côncavos contínuos e descontínuos, ou seja, interrompidos por trechos cujas declividades não estão ajustadas aos demais. Os segmentos côncavos investigados são esculpidos em riodacitos e basaltos vesiculares, devido à menor resistência à erosão desses tipos litológicos. A inserção do canal em zonas fraturadas melhora o ajuste das declividades dos segmentos côncavos, traduzindo-se em aumento do coeficiente de determinação $\left(\mathrm{R}^{2}\right)$. O índice de concavidade nos riodacitos é $-0,79$ e nos basaltos vesiculares, $-1,05$. Embora a diferença nos índices possa ser devido ao não fraturamento tectônico dos riodacitos, a mesma sugere que os basaltos vesiculares são menos resistentes à erosão fluvial.
\end{abstract}

Palavras-chave: erosão fluvial; perfil longitudinal; basaltos; riodacitos; Formação Serra Geral.

\begin{abstract}
Fluvial erosion over volcanic rocks: some inferences from concave segments of longitudinal profiles. The research sought to identify factors that control the homogeneity of the resistance to fluvial erosion over volcanic rocks, which lead to the formation of concave segments in the longitudinal profiles of rivers. Through cartographic and field surveys of geological and geomorphological data, and using the slope-area relationship, we investigated the role of lithological characteristics and tectonic fracturing in the formation of concave segments in a small channel installed in the basalts and rhyodacites of the Serra Geral Formation, in Parana State, Brazil. The slope-area relationship in the form of a power function identified the existence of continuous and discontinuous concave segments, that is, segments interrupted by reaches whose slopes are not adjusted to the others. The concave segments investigated are carved in vesicular basalts and rhyodacites due to the lower resistance to erosion of these rock types. The insertion of the channel in fractured zones improves the slope adjustment of the concave segments, resulting in an increase in the coefficient of determination $\left(\mathrm{R}^{2}\right)$. The index of concavity is -0.79 in rhyodacites and -1.05 in the vesicular basalts. Although this difference may be due to non-tectonic fracturing of rhyodacites, it suggests that the vesicular basalts are less resistant to fluvial erosion.
\end{abstract}

Keywords: fluvial erosion; longitudinal profile; basalts; rhyodacites; Serra Geral Formation.

\section{INTRODUÇÃOO Os perfis longitudinais de rios} desenvolvidos sobre rochas vulcânicas, principalmente basaltos, são caracterizados por possuírem configurações escalonadas (Seidl \& Dietrich 1992, Seidl et al. 1994, Stock \& Montgomery 1999, Lima 1999a). Nos rios do Planalto Basáltico da Bacia do Paraná, o escalonamento é devido às variações nos padrões de fraturamento e de vesiculação das rochas vulcânicas (Leinz 1949, Barcha \& Arid 1971) e também às interferências tectônicas (Lima 1999a, 2009, Bartorelli 2005). Entretanto, destoando do padrão geral, têm sido constatados nesses rios segmentos de perfil côncavo, embutidos no perfil maior. Até o momento, esses segmentos não foram descritos e nem suas causas, investigadas.
Perfis longitudinais côncavos, ou com forte tendência à concavidade, desenvolvem-se nas mais variadas condições de substrato litológico, como atestam aqueles levantados por vários autores em diversos ambientes climático-geológicos (Shepherd 1985, Ohmori 1996, Rãdoane et al. 2003). Vários aspectos físicos estão envolvidos na elaboração de perfis côncavos, tais como a variação da granulometria da carga do leito por abrasão rio abaixo, a erosão regressiva das rupturas de declive e o aumento longitudinal da vazão. Para uma concisa revisão sobre esses aspectos, o trabalho de Sinha \& Parker (1996) constitui um bom referencial. Os perfis côncavos indicam que as variações na resistência à erosão são minimizadas, de 
modo que a declividade diminui rio abaixo em função do aumento da vazão (Wolman 1955).

Em sistemas fluviais de leito misto rochoso-aluvial, diferentemente dos sistemas aluviais, o grau de concavidade pode ser diretamente afetado por variações longitudinais na litologia, no fluxo de sedimentos e nas interferências tectônicas (Hack 1973, Shepherd 1985, Whipple \& Tucker 2002). De modo geral, pode-se dizer que a taxa de diminuição da declividade pode ser diferente dependendo da erodibilidade do substrato rochoso (Stock \& Montgomery 1999). Quando ocorrem afloramentos com diferentes resistências ao longo de um canal, o perfil longitudinal tende a ajustar as declividades, assim como as outras variáveis da geometria hidráulica (Montgomery \& Gran 2001). A resistência à erosão pode ser caracterizada por aquela da rocha intacta (sem fraturas), porém a dos maciços rochosos pode ser alterada pelas características do fraturamento, que pode variar conforme a anisotropia das deformações tectônicas.

Nos basaltos da Bacia do Paraná há dois tipos de níveis litológicos com resistência de rocha intacta diferente, que são os níveis vesiculares e maciços (Lima 2009a e b). Ambos os níveis são fraturados pelo processo de contração da lava na fase de resfriamento dos derrames. Esse fato, em princípio, homogeneíza a resistência à erosão dos dois níveis litológicos, fazendo com que a diferença na resposta erosiva entre eles tenha mais relação com a diferença de resistência da rocha intacta, que implica em diferenças de processos erosivos operantes. Enquanto o arrancamento hidráulico predomina como processo erosivo fluvial nas unidades maciças, levando à formação das zonas de ruptura, nas unidades vesiculares há interação entre abrasão e arrancamento, que associado à baixa resistência da rocha intacta resulta em esculturação dos trechos de baixa declividade relativa (Lima 2009a e b). A observação dessas relações levou à hipótese de que os segmentos côncavos talvez fossem desenvolvidos em níveis vesiculares.

Outro aspecto também poderia influenciar a homogeneidade na resposta geomorfológica. A tectônica associada aos esforços da movimentação da placa sul-americana tem deixado uma intrincada rede de fraturamento sobre as coberturas sedimentar e vulcânica da Bacia do Paraná (Soares et al. 1982, Lima 1999b). As zonas fraturadas tectonicamente reduzem a resistência do substrato e homogeneízam a suscetibilidade à erosão fluvial (Wohl 2008). Em face disso, outra hipótese aventada para explicar a presença de segmentos côncavos seria a inserção dos canais em zonas onde a resistência à erosão tivesse diminuído via fraturamento tectônico.

A relativa homogeneidade erosiva dos basaltos vesiculares e a homogeneização produzida pelos fraturamentos tectônicos foram investigadas nesta pesquisa, buscando sua relação com os segmentos côncavos dos perfis longitudinais dos rios. O entendimento dessa relação permite lançar algumas luzes sobre a questão da dinâmica da incisão fluvial em basaltos, que possui um comportamento diferenciado e pouco compreendido.

ÁREA DE ESTUDO O canal selecionado para estudo faz parte do Rio Guabiroba, que pode ser considerado como o segmento de cabeceira, aqui denominado de canal G1 (Fig. 1). Localizado no município de Guarapuava, Centro-sul do Estado do Paraná, este rio flui para Oeste no reverso da escarpa arenito-basáltica, localmente denominada de Serra da Esperança e que constitui parte da Escarpa da Serra Geral. O rio Guabiroba faz parte da Bacia do Rio das Pedras, formador do Rio Jordão, que, por sua vez, é um dos integrantes principais da Bacia do Rio Iguaçu.

O Rio Guabiroba se estende por $11,5 \mathrm{~km}$ e tem uma área de drenagem de aproximadamente $23 \mathrm{~km}^{2}$, mas o canal G1 se estende por apenas $2,91 \mathrm{~km}$ e possui área de drenagem de $4,1 \mathrm{~km}^{2}$. A escolha de tal canal ocorreu devido a vários fatores, dentre os quais se destacam: a condição de drenagem que corta transversalmente o limite entre rochas vulcânicas ácidas e básicas e as condições de campo, que permitiram um levantamento mais detalhado das características litológicas do leito.

O Rio Guabiroba possui muitas características comuns dos rios do Planalto Basáltico Paranaense. A principal é seu leito misto: trechos rochosos entremeiam-se a outros com fina e transiente cobertura aluvial, cuja granulometria varia de areia grossa até matacões (Lima \& Binda 2008). Ao longo do canal G1 as condições mistas se repetem. No entanto, pelo fato de ser zona de cabeceira fortemente entalhada, blocos e matacões são comumente encontrados recobrindo o leito.

A Bacia do Rio Guabiroba é esculpida em basaltos toleíticos da unidade básica inferior da Formação Serra Geral. A morfologia dos derrames é predominantemente do tipo simples, conforme a denominação de Cas \& Wright (1987). Feições características de derrames pahoehoe, como estruturas tipo "pasta de dente", foram identificadas na área do canal G1. Na zona do divisor, ou mais exatamente na área em que nasce o canal G1, encontram-se remanescentes da cobertura 
formada por rochas ácidas do tipo Chapecó, constituída por riodacitos porfiríticos (Fig. 2). Esse remanescente possivelmente não é o único, pois, ao longo do divisor da bacia, a morfologia em platôs estreitos é bastante sugestiva da existência dessas rochas ácidas. Os riodacitos formam um platô extenso e contínuo situado cerca de $10 \mathrm{~km}$ mais a Oeste, onde está situada a cidade de Guarapuava.

A rede de canais do Rio Guabiroba apresenta uma notável assimetria, com os maiores canais situados no lado esquerdo (Fig. 1). Tal assimetria é sugestiva de basculamento tectônico de blocos. Porém, o direcionamento dos canais para NNW não é uma condição à direção do mergulho geral, que é para NE, mas uma resposta à inserção dos canais em zonas de fraturas. Os blocos que basculam para NE são delimitados por grandes falhas de direcionamento NE que transcendem os limites da Bacia do Rio Guabiroba. O canal G1, quando inflete para SW (Fig. 2), entra em uma zona fraturada irregular que interliga dois segmentos bem configurados de uma dessas falhas.

Aspecto notável no canal G1 é sua inserção em zonas fraturadas em mais da metade de seu percurso (Fig. 2). O canal instala-se em um bloco falhado e a metade final do seu percurso é em falhas que bordejam esse bloco no lado noroeste. No trecho final, o canal G1 tem orientação SE-NW, bordejado por falhas paralelas, e assume características plenamente aluviais.

\section{MATERIAIS E MÉTODOS}

Procedimentos gerais A primeira etapa da pesquisa compreendeu o levantamento do perfil longitudinal do Rio Guabiroba. Os exames preliminar e qualitativo do perfil permitiram selecionar o canal G1 pelos motivos aventados anteriormente. A obtenção do perfil e das áreas de drenagem correspondentes a cada trecho do canal G1 foi realizada sobre carta topográfica, na escala 1:10.000 (equidistância das curvas igual a $5 \mathrm{~m}$ ), em meio digital e no ambiente do aplicativo SPRING 5.1.5, desenvolvido pelo Instituto Nacional de Pesquisas Espaciais, sendo os dados, em seguida, tratados em planilha eletrônica. Por meio do perfil longitudinal, obteve-se a declividade de cada trecho. Para efeito da pesquisa, um trecho corresponde a um segmento situado entre duas curvas de nível consecutivas, e sempre que se menciona uma ordem sequencial de trechos, esta é sempre de montante para jusante.

Com os dados de declividade e área, foi gerado o gráfico de relação entre essas variáveis. Os segmentos

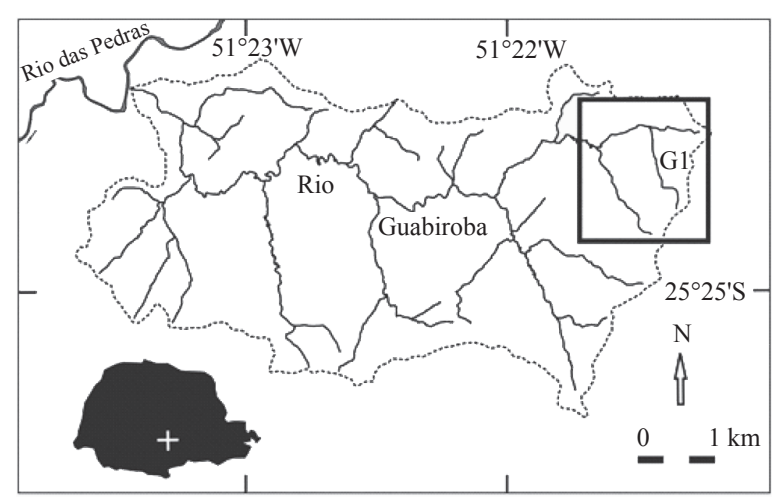

Figura 1 - Localização da área de estudo. O quadro em que aparece o canal G1 corresponde à Fig. 2.

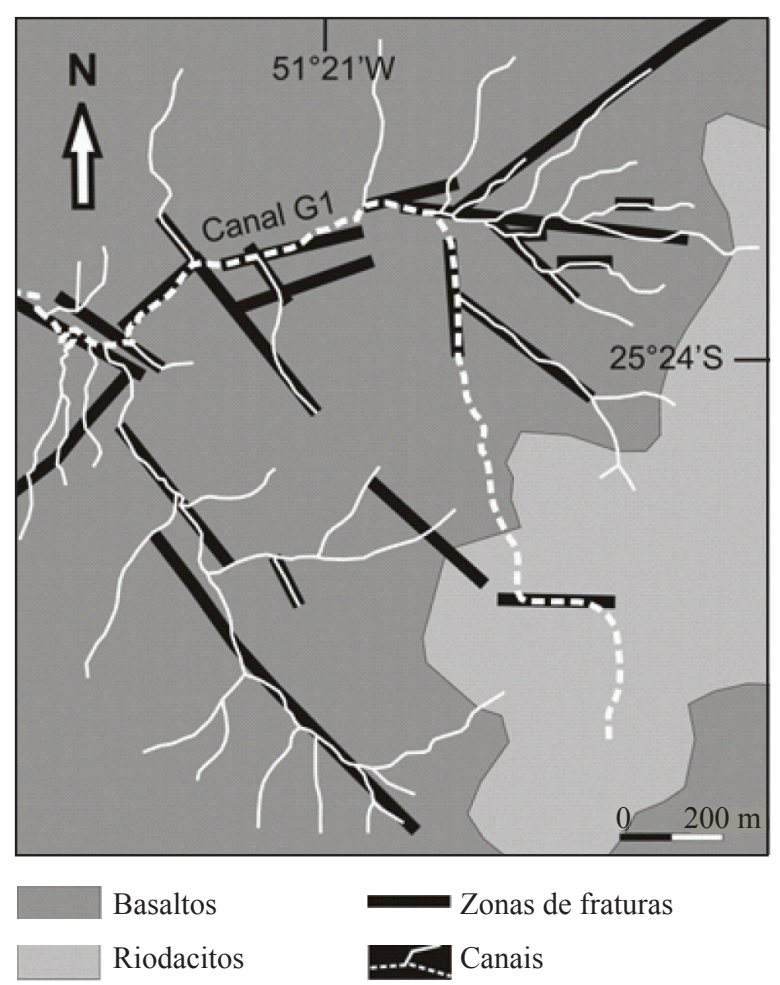

Figura 2 - Mapa geológico simplificado da área de estudo.

côncavos foram analisados separadamente, estabelecendo-se para cada um o chamado modelo declive-área. A base conceitual de tal modelo tem sido utilizada na análise da incisão fluvial em leitos rochosos desde os trabalhos de Howard \& Kirby (1983). O modelo é descrito por uma função potência do tipo (Eq. 1):

$\mathrm{S}=\mathrm{kA}^{-\theta}$

onde, $\mathrm{S}$ é a declividade, A é a área de drenagem, $\mathrm{k}$ é um coeficiente considerado como índice de declividade e $\theta$ é uma constante empírica considerada como índice de concavidade (Flint 1974, Whipple 2004). 
Em campo foi executado o levantamento geológico para identificação das características litológicas - especialmente a vesiculação - do substrato do canal selecionado. As condições de acesso ao canal, devido à vegetação densa e ao relevo íngreme, e ainda a presença de cobertura do leito rochoso por material colúvio-aluvial, constituíram fatores restritivos no levantamento. Por isso, nem todos os trechos do canal tiveram suas características litológicas diretamente identificadas em campo, em alguns a litologia foi inferida pela homogeneidade dos declives.

Para análise da correspondência espacial entre estruturas tectônicas e segmentos côncavos, utilizou-se como base o mapa estrutural da Bacia do Rio das Pedras (Lima 2009). Sobre essa base efetuou-se um detalhamento das estruturas lineares na área correspondente ao canal G1, utilizando-se a interpretação dos elementos de drenagem e de relevo (Soares et al. 1981).

Perfil côncavo: conceitos e identificação O perfil longitudinal de um rio pode ser descrito de forma simples como sendo a relação existente entre a altimetria e a distância da nascente. Um perfil de forma côncava perfeita deve apresentar, rio abaixo, uma diminuição gradual da declividade do canal. Naturalmente, esse tipo de condição ideal raramente acontece e o que se tem na realidade são perfis com irregularidades, ou seja, com trechos cujas declividades não se enquadram na sequência de diminuição gradual. As irregularidades podem ser formadas por trechos com declividades ou maiores ou menores do que as esperadas. O canal G1 é um exemplo que se enquadra em tal conceito (Fig. 3).
A visualização dos perfis côncavos é comprometida, algumas vezes, pela escala cartográfica utilizada para levantamento dos dados. Escalas menores tendem a eliminar as irregularidades, portanto, se o canal possui um perfil geral côncavo isso tende a ser realçado. Escalas maiores mostram mais detalhes e permitem, por vezes, identificar segmentos côncavos embutidos no perfil geral, que pode não necessariamente possuir uma configuração côncava.

Embora os perfis longitudinais em escala de detalhe permitam visualizar melhor os segmentos côncavos, do ponto de vista da relação processo-forma a plotagem declive-área constitui uma ferramenta mais eficiente. $\mathrm{O}$ uso da relação declive-área na presente pesquisa permitiu a melhor definição e ampliação do próprio conceito de perfil côncavo. Nesse tipo de plotagem é possível verificar o grau de ajuste morfológico dos diversos trechos fluviais contíguos. Em outras palavras, é possível identificar se a resistência à erosão permanece constante ao longo de um segmento de canal e, portanto, se a variação da declividade está ajustada à variação da vazão (Wolman 1955). Na plotagem dos dados, os segmentos côncavos aparecem como alinhamentos de pontos, cuja definição pode ser fornecida pelos índices de concavidade e declividade (Eq. 1). O ajuste morfológico dos trechos pode ser medido pelo coeficiente de determinação $\left(\mathrm{R}^{2}\right)$ inerente à função potência que representa o modelo declive-área.

Outra vantagem observada no uso da relação declive-área é a identificação de que trechos com mesma resistência à erosão, mesmo estando separados por trechos com resistências diferentes,
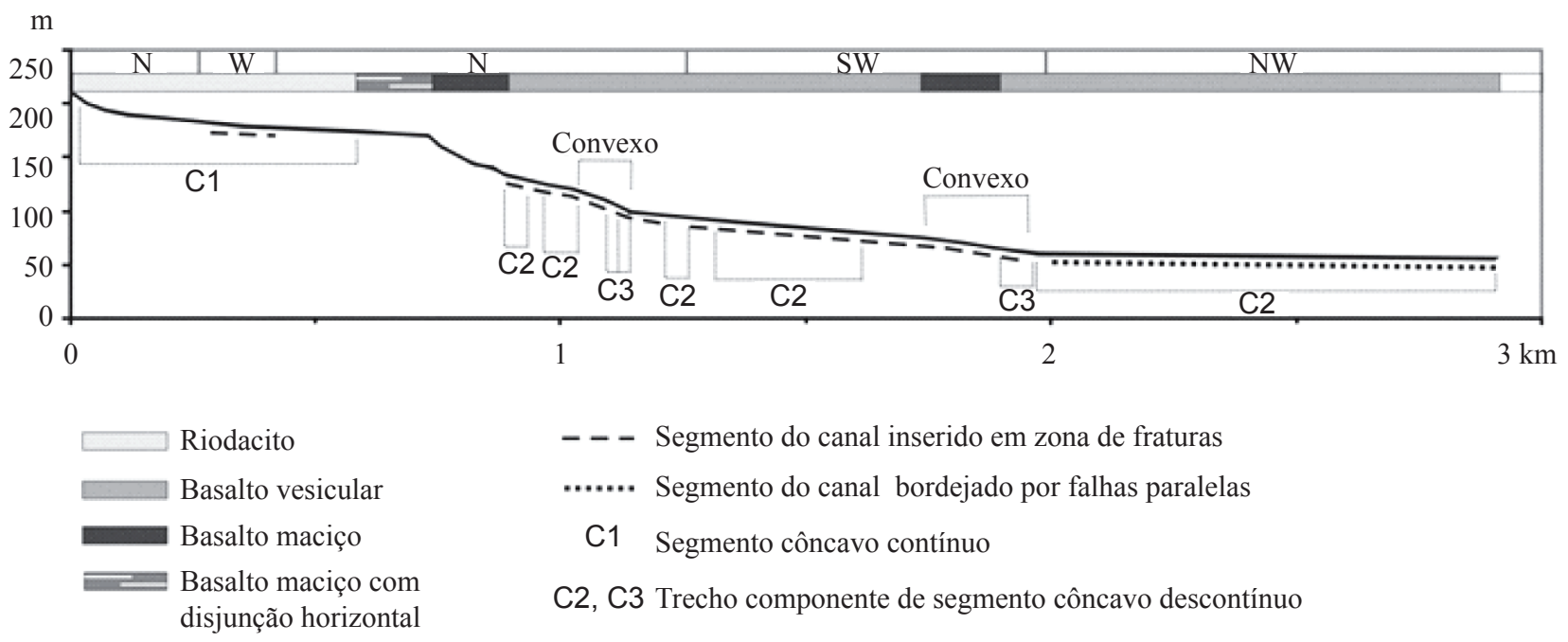

- - - Segmento do canal inserido em zona de fraturas
....... Segmento do canal bordejado por falhas paralelas
C1 Segmento côncavo contínuo
C2, C3 Trecho componente de segmento côncavo descontínuo

Figura 3 - Perfil longitudinal do canal G1. As anotações N, W, SW e NW indicam as direções gerais dos segmentos do canal. O valor zero da escala vertical corresponde ao nivel da desembocadura do Rio Guabiroba, tomado como base inicial das medidas, não correspondendo, portanto, às altitudes sobre o nível do mar. 
ajustam-se morfologicamente em função da vazão. Esse tipo de situação pode criar segmentos côncavos descontínuos, os quais não são facilmente identificáveis na plotagem dos perfis longitudinais.

Um aspecto importante dos segmentos descontínuos é a possibilidade de interpretações geomorfológica e geológica. Por eles, apenas analisando a plotagem declive-área, identificam-se trechos que possuem uma mesma resistência à erosão, o que indica, sobretudo, características litológicas similares.

As irregularidades notadas nos declives de um segmento côncavo contínuo constituem pequenas zonas de ruptura que dividem a continuidade de um perfil, apenas que nesses casos não são/estão suficientemente grandes a ponto de impedir a identificação da concavidade. Nos segmentos descontínuos as irregularidades podem ser grandes, porém a evolução morfológica-erosiva das zonas de ruptura tende a eliminá-las, ou pelo menos atenuá-las (Gardner 1983). Nos basaltos do Havaí, a evolução das rupturas de declive foi alvo de estudos inconclusivos (Seidl et al. 1992), enquanto que na Bacia do Paraná foi considerada inexistente (Leinz 1949). Estudos recentes, entretanto, mostram que as zonas de ruptura nos basaltos da Bacia do Paraná apresentam expressões de evolução morfológica e não apenas de retração paralela (Lima 2009). Desse modo, segmentos côncavos contínuos e descontínuos são dois membros extremos de uma sequência evolutiva.

\section{RESULTADOS E DISCUSSÃO De modo} geral, o canal G1 apresenta um perfil longitudinal que pode ser dividido em duas partes (Fig. 3). A primeira delas vai da nascente até cerca de $0,7 \mathrm{~km}$, na qual é visível o delineamento de um segmento levemente côncavo. A interrupção abrupta desse primeiro segmento dá início ao segundo segmento, que também delineia, de modo geral, uma concavidade. Este, entretanto, apresenta irregularidades na forma das zonas de ruptura. São facilmente visíveis no perfil desse segmento pelo menos duas zonas de ruptura significativas e que constituem segmentos convexos.

Com a análise da relação declive-área aplicada ao canal G1, foi possível identificar que alguns trechos que visualmente parecem estar bem ajustados morfologicamente, na realidade não estão (Fig. 4). Como exemplo pode-se notar o primeiro segmento côncavo, denominado de $\mathrm{C}$, no qual existe um ajuste, mas não tão perfeito como sugere o perfil longitudinal na Fig. 3. A segunda parte do perfil, que pode ser vista na Fig. 3 como um grande segmento côncavo pontuado por irregularidades, é mostrado na Fig. 4 com pelo menos dois segmentos côncavos descontínuos.

A identificação dos trechos que compõem determinado segmento côncavo descontínuo às vezes é dificultada por alguns fatores. Ao longo do canal G1 afloram, alternando-se, níveis de basalto maciço e de basalto vesicular, além de ocorrer interferências tectônicas. Os basaltos maciços geram zonas de ruptura, mas dependendo do seu estilo de fraturamento, o que é notadamente variável dentro dos derrames simples da Formação Serra Geral (Leinz 1949, Arioli et al. 2008, Dutra et al. 2008), podem ser de declividades gerais variáveis. Tal fato significa menor possibilidade de ajustamento dos declives de trechos esculpidos em unidades de derrames distintos. O cruzamento do canal G1 com falhas normais insere no perfil pelo menos duas zonas convexas, impondo o aumento das declividades (Fig. 3). O resultado da combinação desses fatores é a geração de um espalhamento de pontos na plotagem declive-área (Fig. 4), dificultando a identificação das sequências alinhadas que representariam os segmentos côncavos descontínuos. $\mathrm{Na}$ situação do canal G1, dois aspectos foram levados em consideração para determinar os segmentos côncavos em meio ao espalhamento dos dados. O primeiro foi a tendência geral dos dados, que denotam um índice de concavidade $(\theta)$ consistente para a segunda parte do perfil. O segundo foi a determinação das características litológicas em campo.

No canal G1 o primeiro segmento côncavo, denominado de $\mathrm{C} 1$, está esculpido em uma unidade vulcânica ácida, constituída por riodacitos. Esse tipo de unidade litológica é conhecido na região dos derrames da Bacia do Paraná devido ao fato de responder por relevos suaves, denotando sua suscetibilidade erosiva elevada. Até o momento não há estudos sobre os fatores que condicionam essa suscetibilidade, porém os aspectos químico-mineralógicos podem

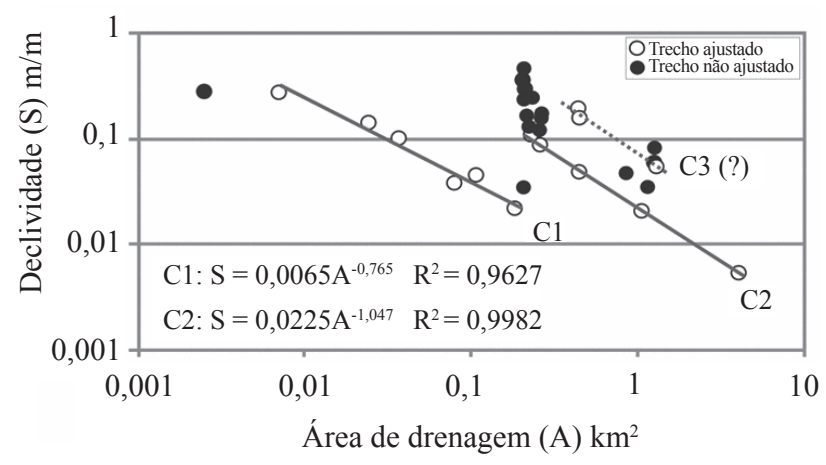

Figura 4 - Relação declive-área para o canal G1. 
ser considerados como fundamentais. Nota-se nessas rochas grande quantidade de fenocristais de feldspato. A reatividade rápida entre os fenocristais e a água é fato evidenciado pelo acelerado intemperismo que esses cristais geralmente apresentam. A decomposição dos fenocristais diminui a densidade da rocha e aumenta sua permeabilidade, acelerando ainda mais a intemperização da matriz. A reação em cadeia leva a rocha a diminuir globalmente sua resistência à erosão. Mesmo que haja diferenciações de fraturamento ao longo dos corpos de riodacito, o que poderia lhe fornecer certa heterogeneidade, a onipresença dos fenocristais de feldspatos possivelmente homogeneíza a resposta geomorfológica, pelo menos no caso estudado.

A existência de uma zona fraturada que controla o direcionamento do canal na parte média do segmento côncavo $\mathrm{C} 1$ aparentemente não influencia as declividades. Isso porque os trechos que estão a montante não se ajustam em fraturas e, no entanto, compõem o segmento côncavo. Na plotagem declive-área (Fig. 4), nota-se que, embora haja a tendência de diminuição da declividade rio abaixo, não há uma perfeita regularidade nessa diminuição. $\mathrm{O}$ significado é que provavelmente haja discretas mudanças na resistência das rochas à erosão. Não se exclui também a possibilidade de haver imprecisões inerentes às fontes cartográficas dos dados. Após o término do segmento $\mathrm{C}$, ocorre um trecho cuja declividade é mais alta, porém não diferindo muito da sequência côncava (Fig. 4), que é formado em basalto maciço com disjunção horizontal e não mais em riodacito.

Os trechos que estão na continuidade são formados por basalto maciço e caracterizam uma zona de ruptura abrupta, a qual, na plotagem do perfil longitudinal (Fig. 3), aparenta ser a cabeceira de um grande segmento côncavo que caracteriza a segunda parte do perfil do canal G1. Porém, a relação declive-área indica um perfil bastante irregular a partir dessa zona de ruptura (Fig. 4). Não há um grande segmento côncavo contínuo e nem mesmo menores que sejam contínuos e estejam embutidos no perfil maior. Pode-se, entretanto, perceber que existem alguns descontínuos. O primeiro a ser identificado é constituído de cinco trechos separados entre si e cujas declividades estão perfeitamente ajustadas (Fig. 4, segmento C2). Os três últimos trechos são constituídos por basalto vesicular. As características litológicas dos dois primeiros trechos da sequência não puderam ser verificadas em campo. Entretanto, pela consistência da relação dos demais trechos em termos de declividade e litologia, possivelmente o segmento como um todo represente a esculturação em basalto vesicular.

É interessante notar que os trechos que compõem o segmento $\mathrm{C} 2$ estão inseridos em zonas fraturadas. A questão que emerge dessa constatação é se o segmento côncavo, ainda que descontínuo, seria devido ao fato de o substrato ser basalto vesicular ou ao ajuste em zonas fraturadas. $\mathrm{O}$ basalto vesicular pode variar em suas características de um derrame para outro ou mesmo dentro de um mesmo derrame. Sobretudo, o grau de vesiculação e o dimensionamento das vesículas são aspectos que poderiam influenciar certa heterogeneidade nas respostas à erosão. $\mathrm{O}$ fraturamento, por sua vez, tenderia a homogeneizar a resposta. Essa poderia ser uma explicação para o excelente ajuste dos pontos que representam o segmento côncavo descontínuo na plotagem declive-área (Fig. 4).

Se a inserção do canal em zonas fraturadas diminui o efeito das heterogeneidades litológicas sobre a resposta geomorfológica, a não inserção não produziria segmentos côncavos, contínuos ou descontínuos, com sequências bem ajustadas. Em outras palavras, a menor resistência dos basaltos vesiculares tenderia a facilitar a erosão dos diferentes trechos, mas as heterogeneidades litológicas poderiam levar à formação de irregularidades no perfil. No canal G1 não se tem registrado outro segmento côncavo, além do $\mathrm{C} 2$, e que seja formado em basaltos vesiculares não fraturados.

São registrados no canal outros trechos esculpidos em basalto vesicular e cujas declividades são mais elevadas do que as dos trechos do segmento côncavo $\mathrm{C} 2$, porém não formam sequências individualizadas que possam ser descritas como segmentos côncavos contínuos ou descontínuos. Três desses trechos parecem apresentar certa tendência que acompanha, em paralelo e em nível mais elevado, a tendência do segmento $\mathrm{C} 2$, sendo por isso identificado com incerteza na Fig. 4 e denominado de C3. Verifica-se que estas três ocorrências correspondem a trechos inseridos em fraturas, e constituem partes das duas principais zonas convexas, as quais são perfeitamente visíveis no perfil longitudinal (Fig. 3). O ajuste em zonas fraturadas explicaria a homogeneização da resistência erosiva dos três trechos. Entretanto, por que esses trechos formariam um segmento côncavo descontínuo à parte (C3), em vez de estarem ajustados ao segmento $\mathrm{C} 2$ ? A resposta pode estar relacionada à origem tectônica das zonas de ruptura em que os referidos trechos estão localizados. Ambas estão situadas imediatamente à montante da inserção do canal em falhas de rejeito 
normal e que delimitam blocos basculados. Os primeiros trechos do alinhamento C3 (montante) têm direcionamento dado por fraturas, porém fluem a favor do mergulho de um bloco estrutural. O último trecho (jusante) desce pelo muro da falha, portanto em direção contrária ao mergulho do bloco. As declividades relativamente elevadas dos trechos demonstram relação com a deformação tectônica.

Como visto no canal G1, os basaltos vesiculares oferecem menor resistência à erosão, ainda mais quando há uniformização da resistência pelo fraturamento tectônico, e podem formar segmentos côncavos descontínuos. Isso não significa que segmentos côncavos contínuos não possam se formar em determinada unidade de basalto vesicular. O problema, neste caso, é que as espessuras dessas unidades geralmente não são muito significativas. Por isso, eventuais segmentos côncavos somente seriam detectados se o levantamento do perfil fosse efetuado com mais detalhes. No canal G1 a grande espessura da unidade vesicular presente no curso médio (Fig. 3) é apenas aparente, resultado do basculamento de bloco para norte.

A comparação do grau de ajuste do segmento $\mathrm{C} 2$, formado nos basaltos vesiculares, e do $\mathrm{C} 1$, formado nos riodacitos, fornece outro exemplo do efeito das heterogeneidades sobre o ajuste das declividades. O segmento $\mathrm{C} 1\left(\mathrm{R}^{2}=0,962\right)$ é menos ajustado que o $\mathrm{C} 2\left(\mathrm{R}^{2}=0,998\right)$. A razão disso é, provavelmente, o fato de o segmento $\mathrm{C} 1$ não apresentar inserção significativa em zona de fraturas tectônicas, como mencionado. Em consequência, os processos erosivos estão sujeitos às diferenças de resistência da rocha intacta ou àquelas impostas por fraturas menores, eventualmente tectônicas, porém dispersas na unidade dos riodacitos.

O índice de concavidade nos riodacitos é $-0,79$, enquanto que nos basaltos vesiculares, é de $-1,05$. Em outras palavras, a taxa de diminuição das declividades rio abaixo nos riodacitos do segmento $\mathrm{C} 1$ é mais baixa que nos basaltos vesiculares do C2. Em termos comparativos e analisando apenas o aspecto litológico, poder-se-ia entender que os basaltos vesiculares são menos resistentes à erosão, de modo que a onda regressiva de erosão avança para montante com mais rapidez do que nos riodacitos. Os índices de declividade (k) são diferentes para os dois segmentos, sendo maior para os basaltos vesiculares, o que parece corroborar a ideia de que o comportamento erosivo seja mesmo uma função das diferenças litológicas. Futuras investigações deverão avaliar se o fraturamento tectônico nos riodacitos modifica o índice de concavidade, aproximando-o daquele dos basaltos vesiculares.

CONCLUSÕES A aplicação da relação declive-área a partir de um canal esculpido em rochas vulcânicas permitiu não somente caracterizar precisamente os segmentos côncavos, mas também identificar a formação de segmentos côncavos descontínuos, ou seja, interrompidos por trechos cujas declividades não estão ajustadas aos demais.

No canal analisado identificou-se um segmento côncavo contínuo esculpido em rochas vulcânicas ácidas. Atribui-se essa ocorrência aos aspectos químico-mineralógicos dos riodacitos, que os tornam altamente suscetíveis ao intemperismo e com a consequente diminuição da resistência à erosão.

Outro segmento côncavo foi identificado na continuidade do perfil, do tipo descontínuo e esculpido em basaltos vesiculares. Os trechos que compõem esse segmento estão em grande parte de sua extensão inseridos em zonas fraturadas tectonicamente. Outros esculpidos em basalto vesicular, entretanto, apresentam declividades maiores e podem ou não formar segmentos côncavos. Nestes casos, constatou-se relação de alguns declives com deformação tectônica produzida por falha. A inserção do canal em zonas fraturadas melhora o ajuste das declividades dos segmentos côncavos, pois confere mais homogeneidade na resistência à erosão fluvial. Esse fato pode ser analisado objetivamente pelo coeficiente de determinação $\left(\mathrm{R}^{2}\right)$ dos segmentos côncavos.

O índice de concavidade calculado para o segmento côncavo nos riodacitos é $-0,79$, enquanto que, para o segmento nos basaltos vesiculares, é $-1,05$. A diferença desses sugere que os basaltos vesiculares são menos resistentes à erosão fluvial, de modo que a onda regressiva de erosão avança para montante com mais rapidez do que nos riodacitos, tornando o perfil mais côncavo. Os índices de declividade também são diferentes, sendo maior para os basaltos vesiculares, o que corrobora a interpretação do comportamento desta litologia frente à erosão fluvial. Não se descarta, porém, a possibilidade de a diferença nos índices de concavidade estar relacionada a não inserção em zonas fraturadas do segmento instalado sobre os riodacitos.

AGRADECIMENTOS Os trabalhos de campo tiveram a valiosa colaboração de Marlon França Soares, Juliana Amaral e Elisangela Maria Octaviano, alunos do curso de geografia da Universidade Estadual do Centro-Oeste, Guarapuava, no Paraná. 


\section{Referências}

Arioli E.E., Licht O.A.B., Vasconcellos, E.M.G., Bonnet K.L., Santos, E.M. 2008. Faciologia vulcânica da Formação Serra Geral na região de Guarapuava, Paraná. In: Simpósio de Vulcanismo e Ambientes Associados, 4, Anais. Disponível em: http://petro. rc.unesp.br/vulcanismo/. Acesso em: 15/01/2011.

Barcha S.F. \& Arid F.M. 1975. Origem das cachoeiras da Bacia do Alto Paraná. Revista Brasileira de Geociencias, 5:120-135.

Bartorelli A. 2005. Origem das grandes cachoeiras do Planalto Basáltico da Bacia do Paraná: evolução quaternária e geomorfologia. In: Montesso-Neto V., Bartorelli A., Carneiro C., Brito-Neves B.B. (Org.) Geologia do continente sul-americano: evolução da obra de Fernando Flávio Marques de Almeida. São Paulo, Beca, p. 75-111.

Cas R.A.F. \& Wright J.V. 1987. Volcanic successions: modern and ancient. London, Allen \& Unwin, 528 p.

Dutra C.R., Ferreira C.H.N., Mesquita M.J., Gomes M.E.B., Bongiolo E.M., Arioli E.E. 2008. Variações estruturais e texturais no derrame Salto Segredo, Formação Serra Geral, Paraná. In: Simpósio de Vulcanismo e Ambientes Associados, 4, Anais. Disponível em: http://petro.rc.unesp.br/vulcanismo/. Acesso em: 15/01/2011.

Flint J.J. 1974. Stream gradient as a function of order, magnitude and discharge. Water Resources Research, 10:969-973.

Gardner T.W. 1983. Experimental study of knickpoint and longitudinal profile evolution in cohesive, homogeneous material. Geological Society of American Bulletin, 94:664-672.

Hack J.T. 1973. Stream profile analysis and stream gradient index. Journal of Research of the US Geological Survey, 1:421-429.

Howard A.D. \& Kirby G. 1983. Channel changes in badlands. Geological Society of American Bulletin, 94:739-752.

Leinz V. 1949. Contribuição à geologia dos derrames basálticos do sul do Brasil. Boletim FFCL/USP, Geologia, 5:1-61.

Lima A.G. 2009. Controle geológico e hidráulico na morfologia do perfil longitudinal em rio sobre rochas vulcânicas básicas da Formação Serra Geral no Estado do Paraná. Tese de Doutorado, Departamento de Geociências, Universidade Federal de Santa Catarina, $219 \mathrm{p}$.

Lima A.G. 1999a. Avaliação do controle geológicoestrutural no comportamento da rede de drenagem do Rio das Pedras, Guarapuava - PR. Dissertação de Mestrado, Instituto de Geociências e Ciências Exatas, Universidade Estadual Paulista, Rio Claro, 142 p.

Lima A.G. 1999b. Orientações de canais na bacia do Rio das Pedras (Guarapuava - PR). Geociências, 18:245-260.
Lima A.G. \& Binda A.L. 2008. Vazão de margens plenas em canal misto rochoso-aluvial: um teste preliminar de equações empíricas. In: UGB, Simpósio Nacional de Geomorfologia, Anais, CD Rom.

Montgomery D.R. \& Gran K.B. 2001. Downstream variations in the width of bedrock channels. Water Resources Research, 37:1841-1846.

Ohmori H. 1996. Morphological Characteristics of longitudinal profiles of rivers in South Island, New Zealand. Bulletin of the Department of Geography, 28:1-23.

Rãdoane M., Rãdoane N., Dumitriu D. 2003. Geomorphological evolution of river profiles in the Carpathians. Geomorphology, 50:293-306.

Seidl M.A. \& Dietrich W.E. 1992. The problem of bedrock channel erosion. Catena Supplement, 23:101-124.

Seidl, M.A., Dietrich W.E., Kirchner J.W. 1994. Longitudinal profile development into bedrock: an analysis of Hawaiian channels. Journal of Geology, 102:457-474.

Sinha S.K. \& Parker G. 1996. Causes of concavity in longitudinal profiles of rivers. Water Resources Research, 32:1417-1428.

Shepherd R.G. 1985. Regression analysis of river profiles. Journal of Geology, 93:377-384.

Soares P.C., Barreto M.L.K., Redaelli R. 1981. Aplicação da análise morfoestrutural em semidetalhe com fotos aéreas na Bacia do Paraná. In: SBG/NSP, Simpósio Regional de Geologia, 3, Anais, p. 217-225.

Soares P.C., Barcelos P.E., Csordas S.M., Mattos J.T., Ballieiro M.G., Meneses P.R. 1982. Lineamentos em imagens de Landsat e radar e suas implicações no conhecimento tectônico da Bacia do Paraná. In: Simpósio Brasileiro de Sensoriamento Remoto, 2, Anais, p. 201-216.

Stock J.D. \& Montgomery D.R. 1999. Geologic constraints on bedrock river incision using stream power law. Journal of Geophysical Research, 104:4983-4993.

Whipple K.X. 2004. Bedrock rivers and the geomorphology of active orogens. Annual Review of Earth and Planetary Sciences, 32:151-185.

Whipple K.X. \& Tucker G.E. 2002. Implications of sediment flux dependent river incision models for landscape evolution. Journal of Geophysical Research, 107, doi: 10.1029/2000JB000044.

Wohl E. 2008. The effect of bedrock jointing on the formation of straths in the Cache la Poudre River drainage, Colorado FrontRange. Journal of Geophysical Research, 113:F01007, doi:10.1029/2007JF000817.

Wolman G. 1955. The nature channel of Brandywine Creek, Pennsylvania. US Geological Survey Professional Paper, 271.

Manuscrito ID 20836

Recebido em: 18/02/2011 Aprovado em: 23/04/2012 